\title{
Anthropogenic footprint of climate change in the June 2013 northern India flood
}

\author{
Changrae Cho ${ }^{1}$, Rong Li ${ }^{1,2}$, S.-Y. (Simon) Wang ${ }^{1,2}$, Jin-Ho Yoon ${ }^{3}$, Robert R. Gillies ${ }^{1,2}$
}

(1) Utah Climate Center, Utah State University, Logan, UT, USA

(2) Department of Plants, Soils, and Climate, Utah State University, Logan, UT, USA

(3) Pacific Northwest National Laboratory, Richland, Washington

Corresponding to: simon.wang@usu.edu

Running head: Anthropogenic impact on June 2013 Indian flood

\section{Abstract}

During 13-17 June 2013, heavy rainfall occurred in the northern Indian state of Uttarakhand and led to one of the worst floods in history and massive landslides, resulting in more than 5,000 casualties and a huge loss of property. In this study, meteorological and climatic conditions leading up to this rainfall event in 2013 and similar cases were analyzed for the period of 1979-2012. Attribution analysis was performed to identify the natural and anthropogenic influences on the climate anomalies using the historical single-forcing experiments in the Coupled Model Intercomparison Project Phase 5 (CMIP5). In addition, regional modeling experiments were carried out to quantify the role of the long-term climate trends in affecting the rainfall magnitude of the June 2013 event. It was found that (a) northern India has experienced increasingly large rainfall in June since the late 1980s, (b) the increase in rainfall appears to be associated with a tendency in the upper troposphere towards amplified short waves, and (c) the phasing of such amplified short waves is tied with increased green-house gases (GHGs) and aerosols. In addition, a regional modeling diagnosis attributed 60-90\% of rainfall amounts in the June 2013 event to post-1980 climate trends. 
30 Keywords: Extreme events, climate and weather interactions, greenhouse gas

31 (GHG) forcing, synoptic wave train, CMIP5, WRF model, cold air intrusion

\section{1. Introduction}

During 13-17 June 2013, heavy rainfall occurred in the northern Indian state of Uttarakhand, located on the windward side of the Himalayan ranges. The torrential rain together with rapid snowmelt led to extreme flooding and widespread landslides, causing thousands of deaths and a huge loss of property (Dubey et al. 2013). In addition to the devastation in Uttarakhand, this event also affected other parts of India including Himachal Pradesh, Haryana, Delhi and Uttar Pradesh, as well as western Nepal and parts of Tibet (Dubey et al. 2013). In recent years, similar heavy rainfall and widespread flood events have become increasingly frequent in northern South Asia. For example, an extreme rainfall event occurred in northern Pakistan during July 2010, resulting in floods that killed about 3,000 and affected around 20 million people (Hong et al. 2011; Lau and Kim 2012; Wang et al. 2011b). More recently (2-6 September 2014), some regions in India (Jammu and Kashmir) and Pakistan (Azad Kashmir, Gilgit-Baltistan and Punjab) underwent extreme floods caused by heavy rainfall, leading to more than 500 deaths (Najar and Masood, 2014).

A number of recent studies have investigated these heavy rainfall events, but most studies focused on either the synoptic or the mesoscale meteorological conditions of individual events (e.g., Hong et al. 2011; Houze et al. 2011; Joseph et al. 2014; Martius et al. 2013); few studies have analyzed the large-scale features and long-term climate 
52 linkages. A recent study (Singh et al. 2014) conducted statistical analysis and concluded

53 that the June 2013 rainstorm in northern India was at least a century-scale event, and the

54 probability for such an event to occur has increased in the present climate compared to

55 the preindustrial climate. However, knowledge regarding the mechanisms leading to the

56 reported increased probability in extreme rainfall is lacking. Isolating the climate change

57 impact on any individual storm or rainfall event is challenging, but such information is

58 necessary for disaster planning and mitigation. Thus, the goals of this study are to

59 identify common features in the meteorological conditions accompanying the June 2013

60 event and to investigate the mechanism through which climate change influences similar

61 rainfall events, using observational data and climate model simulations. The data and

62 modeling system used in this research are described in Section 2. The results are

63 presented in Section 3. A summary and discussions are provided in Section 4.

2. Data and Methods

66

\subsection{Data}

To depict evolution of the heavy rainfall cases, observational rainfall was obtained from the 3-hourly Climate Prediction Center (CPC) Morphing technique precipitation

69 (CMORPH) (Joyce et al. 2004) with the resolution of $0.25^{\circ} \times 0.25^{\circ}$. Since the CMORPH

70 exists only after December 2002, monthly global precipitation data from NOAA's

71 Precipitation Reconstruction over Land (PREC/L) (Chen et al. 2002) for the period of 72 1948-present was used to analyze the long-term climatology and trend. The PREC/L

73 dataset is based on the gauge observations over 17,000 stations worldwide, and the 74 resolution used in this study is $1.0^{\circ} \times 1.0^{\circ}$. For meteorological variables including wind, 
temperature, relative humidity, and geopotential height, the NCEP/NCAR Reanalysis

76 (Kalnay et al. 1996) for the period 1948-present was used.

To perform detection and attribution analyses, we used the fully coupled climate 78 model simulations in the Coupled Model Intercomparison Project Phase 5 (CMIP5)

79 (Taylor et al. 2012). To isolate the climate change signal, four sets of the CMIP5

80 Historical Single-Forcing Experiments were used: (a) one driven solely by natural forcing 81 (e.g., solar cycle and volcano) (denoted as NAT), (b) one forced solely by greenhouse 82 gases (denoted as GHG), (c) one driven solely by aerosols forcing (denoted as Aero), and

83 (d) one driven with all natural and anthropogenic forcing sources (Taylor et al. 2012). A 84 total of 10 coupled models were used in this study, and the details of these models are 85 listed in Table 1.

\subsection{Regional climate model experiments}

Simulations of the June 2013 Indian rainfall event were carried out using the

89 Weather Research and Forecasting (WRF) model version 3.5 (http://www.wrf90 model.org/index.php). Initial and lateral boundary conditions were obtained from the

91 NCEP-DOE Reanalysis2 (Kanamitsu et al. 2002), which is 6-hourly data with a 92 resolution of $2.5^{\circ} \times 2.5^{\circ}$. WRF simulations were conducted for the period of 1-21 June 932013 and the first 11 days were treated as spin-up. The model land use was derived from 94 the United States Geological Survey (USGS) 24-category global 30-second dataset. The 95 spatial resolution was set to $30 \mathrm{~km}$, and the simulations used 30 vertical layers up to 50

$96 \mathrm{mb}$. The physics parameterizations included the SBU-YLin scheme for microphysics (Lin 97 and Colle 2011), CAM schemes for radiation (Collins et al. 2006), MYNN level 2.5 
TKE scheme for the Planetary Boundary Layer (PBL) processes (Nakanishi and Niino 2006), and five-layer soil thermal diffusion scheme for land surface processes.

To isolate the effects of climate change on the June 2013 Indian rainfall event, two experiments were designed:

(1) Control simulation forced by the initial and boundary conditions (BC) from the original NCEP-R2 data;

(2) No-trend simulation forced by the BC of the NCEP-R2 from which the post-1980 linear climate trends in all $\mathrm{BC}$ variables were removed. The assumption here is that any long-term trend manifest in the troposphere contains signals that are traceable to anthropogenic climate warming (which is supported by CMIP5 attribution analysis as shown later). Although the long-term changes exhibited by different variables may not be linearly correlated, we have shown in a previous study (Wang et al. 2011a) that the nonlinear effect is generally negligible when it comes to this no-trend simulation approach in South Asia.

\section{Results}

\subsection{The heavy rainfall event in June 2013}

To depict the large-scale environment associated with the June 2013 flood event, we divided the evolution of the rainfall event (8-22 June 2013) into three periods: prestorm (8-12 June), storm (13-17), and post-storm (18-22) periods. In doing so, we focused on the large-scale environment and its evolution. Figures 1a and b show the 5day averages of wind and vorticity fields during the pre-storm period at $200 \mathrm{mb}$ and 700mb, respectively. An upper-level ridge covered most of northern India (Figure 1a), 
121 while the monsoon trough center (Figure 1b) was located on the western coast of the 122 Indian peninsula and the Arabian Sea. Meanwhile a monsoon depression developed over 123 the Bay of Bengal (BoB) as seen in the lower troposphere. These circulation patterns 124 changed considerably during the storm period (Figures 1c and d): First, an upper-level 125 tropospheric trough developed over northern India and appeared to be part of a short126 wave train extending from the Mediterranean Sea to East Asia (Figure 1c). As indicated 127 by Joseph et al. (2014), this trough over northern India induced cold air intrusion in the 128 upper troposphere and subsequently enhanced instability in the region. In the lower 129 troposphere, the BoB depression moved into the Indian subcontinent and merged with the 130 monsoon trough, forming a strong cyclonic circulation over central and northern India. 131 The northern branch of this cyclonic circulation apparently interacted with the Himalaya 132 foothills, which provided orographic lifting and further enhanced rainfall in Uttarakhand 133 and adjoining regions (Joseph et al. 2014). During the post-storm period (Figures 1e and $134 \mathrm{f}$ ), the upper-level trough weakened and the lower-level cyclonic circulation over the 135 Indian peninsula dissipated.

136 The aforementioned analyses show that the June 2013 extreme precipitation event 137 was likely caused by several factors acting collaboratively: (a) deepening of the upper138 level trough leading to increased baroclinicity, cold air intrusion aloft, and enhanced 139 instability with warm and moist air beneath, (b) strong monsoon trough in the lower 140 troposphere merged with a BoB monsoon depression, and (c) interaction of the 141 circulation with a steep topography on the southern side of the Himalayan ranges. These 142 regional meteorological conditions are symptomatically similar to those in other extreme 143 rainfall events in northern South Asia that involved upper-level synoptic waves (Wang et 
144 al. 2011b; Rasmussen et al. 2014).

\section{$146 \quad 3.2$ Comparison with events of similar circulation settings}

147 To investigate whether or not this June 2013 event is singular or recurrent in the 148 observational records and whether there is any systematic long-term change, we first 149 identified cases since 1979 that featured the upper-level circulation setting similar to that 150 of the June 2013 event. Since the midlatitude influence played a certain role (Joseph et al. 151 2014) and such an influence has appeared to intensify (Wang et al. 2011a), we designed 152 two selection criteria for the depiction of upper tropospheric circulations:

153 (1) For pattern recognition: The spatial correlation coefficient of $200 \mathrm{mb}$ geopotential 154 height anomalies in the region $\left(20^{\circ} \mathrm{N}-60^{\circ} \mathrm{N}, 0^{\circ} \mathrm{E}-150^{\circ} \mathrm{E}\right)$ between the June 2013 storm 155 period (13-17 June) and any given 5-day period is greater than 0.6 (i.e. with the p$156 \quad$ value $<0.001)$.

157 (2) For trough intensity: The area-averaged geopotential height at the center of the upper158 level trough (i.e., maximum vorticity in Fig. 1c to the northwest of Uttarakhand) 159 averaged over any given 5-day period is within $60-140 \%$ of that in the $13-17$ June 1602013 storm period.

161 These two criteria have to be met simultaneously to ensure proper identification of the 162 upper-tropospheric circulation pattern and trough strength that both resemble those in the 163 June 2013 event. Based on these criteria, only 5 cases were identified in the past 35 years 164 (1979-2013): 22-26 June 2004, 12-16 June 2007, 28 June-2 July 2009, 28 June-2 July 1652010 , and 28 June-2 July 2011. Apparently these cases only occurred in the last 10 years, 166 implying that this type of meteorological setting (or midlatitude influence) conducive to 
extreme rainfall is likely influenced by climate change.

In Figure 2 we compared the CMORPH precipitation (Figures $2 \mathrm{a}$ and $\mathrm{b}$ ) and geopotential anomalies (Figures 2c-f) between the June 2013 event and the composite of all 5 cases identified previously. The accumulated precipitation in the composite cases does not show any significant amount in Uttarakhand (Figures $2 b$ ), even though the upper-level short-wave train (Figure 2d) shares a similar pattern with the 2013 event (Figure 2c). Why did these previous cases not produce rainfall as heavy as in June 2013 in Uttarakhand? An examination of the $700 \mathrm{mb}$ geopotential height structure gives a hint to this question: While the June 2013 event featured a strong monsoon trough (Figure 2e), the composite cases are characterized by a weak monsoon trough across the Indian subcontinent (Figure 2f). Altogether, these "similar but different" six cases reinforce the previous claim that the June 2013 event occurred due to the unusual coupling of the strong upper-level trough with a strong monsoon trough, and that these two anomalous circulations at different levels do not always synchronize.

Figure 3a displays the time series of June precipitation averaged over Uttarakhand (delineated with a box in Figure 1a), superimposed with an one-sided 20-year running average (black line) and a linear trend after 1988 (red line). Apparently there has been an increasing trend of precipitation during recent decades (with slope of $0.11 \mathrm{~mm} / \mathrm{day} / \mathrm{year}$ at $99 \%$ statistical confidence). As a further examination, Figure $3 \mathrm{~b}$ shows the spatial pattern of the linear trend in the June $200 \mathrm{mb}$ geopotential since 1988, reflecting the maximum precipitation trend. Figure 3c shows the $200 \mathrm{mb}$ geopotential anomalies during the June 2013 event. A low pressure system is revealed in both Figure 3b and 3c to the north of Pakistan, which facilitates upper-level cold air intrusion towards northern India 
190 and western Nepal. This coincidence suggests that the upper-level short-wave train 191 associated with the June 2013 event is embedded in a long-term change in upper

192 tropospheric circulation structure. The coincidence also echoes the finding of Wang et al. 193 (2011b), who analyzed the 2011 Pakistan flood in July and found that the post-1980 trend 194 in the upper troposphere exhibited an amplified short-wave structure similar to that of the 195 circulation anomalies during summer 2011. These observations are supportive of the 196 emerging theory that the jet stream may have become increasingly "meandering"; this 197 leads to an increase in extreme events worldwide (Francis and Vavrus 2012; Wang et al. 198 2013; Screen and Simmonds 2014).

\subsection{Attribution of the climate trend}

The next important question concerns the forcing mechanism that acts to 202 strengthen the upper-level stationary waves near northern India. Here we analyzed the 203 trend of the ensemble-mean $200 \mathrm{mb}$ geopotential heights simulated by ten CMIP5 models

204 for the period 1980-2005, and compared the results between the natural and GHG forcing 205 experiments. As shown in Figure 4a, the simulation driven by all (natural and 206 anthropogenic) forcing sources produced the $200 \mathrm{mb}$ geopotential trends that are in 207 reasonable agreement with the observation: i.e. an amplified wave train with an 208 anomalous low center over central Asia and two anomalous high pressure centers located 209 to the east and west. This result lends confidence in CMIP5 models' performance. 210 However, Figure $4 \mathrm{~b}$ shows that the simulation with only natural forcing produced a 211 circulation structure that does not favor cold air intrusion over northern South Asia. In 212 contrast, both GHG and aerosols forcing simulations (Figures 4c and 4d) produced the 
$213200 \mathrm{mb}$ geopotential trends that are in line with the observation with the deepened trough

214 to the north of Uttarakhand. This suggests that the increased greenhouse gases and likely

215 the increased aerosols collectively caused wave train pattern of the change in the upper-

216 level tropospheric flows. This result corresponds to the previous finding that all 5

217 previous cases having a similar upper-level circulation setting with the June 2013 event

218 occurred only in the last decade. Using three CMIP5 models, Wang et al. (2013) have

219 found that only the GHG forcing experiments produced the amplified short waves during

220 summer. In addition to the change in dynamics, we plotted in Figure 5 the June surface

221 (2-meter) temperature averaged over Uttarakhand superimposed with the post-1988 trend

222 (red line). The surface temperature in Uttarakhand only shows a mild warming trend that

223 did not pass the significance test $(\mathrm{p}>0.1)$. This means that the upper tropospheric

224 cooling is relatively more important for the destabilization and associated precipitation

225 increase as revealed in Figures 3 and 4.

226 When it comes to attribution analysis, the mere use of observational data and

227 model free runs is not adequate to reach robust conclusions. As a complementary

228 approach, sensitivity experiments with WRF were performed (experimental design is

229 detailed in Section 2.2). Figures 6a-c show 5-day average precipitation during the storm

230 event (13-17 June) from the CMORPH as well as the control and no-trend experiments,

231 respectively. The control experiment (Figure 6b) produced rainfall in Uttarakhand that

232 agrees reasonably with the observation, while the no-trend experiment (Figure 6c) grossly

233 underestimated precipitation. Apparently, the removal of long-term trend in the WRF

234 boundary conditions considerably reduced the total storm rainfall. The ratio between the

235 no-trend and control experiments (Figure 6d) indicates a 60-90\% reduction in rainfall 
236 over Uttarakhand (boxed area), and such a reduction in rainfall amounts is considered

237 attributable to the long-term climate change. As further attribution, Figure 6e shows the

238 daily precipitation evolution averaged over Uttarakhand. While the control experiment

239 produced a comparable amount of rainfall with the observation, albeit with a shifted

240 timing (delay) by about one day, the no-trend experiment produced significantly reduced

241 precipitation, i.e., less than $20 \%$ over the entire period of 13-17 June. This result

242 illustrates that, although the rainfall event would still occur regardless of the climate trend

243 or change, the post-1980 climate trend in the atmosphere has significantly aggravated the

244 storm intensity.

245 The mechanism through which the climate trend has contributed to the severity of

246 the June 2013 event is further illustrated through thermodynamic analysis. Figures $7 \mathrm{a}$ and

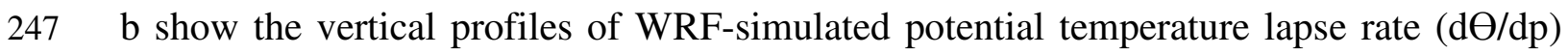

248 and relative humidity averaged over the Uttarakhand region during 13-17 June 2013. The

$249 \mathrm{~d} \Theta / \mathrm{dp}$ of no-trend experiment revealed a discernable stabilization in the $800-650 \mathrm{mb}$

250 layer relative to the control experiment. The increase in stability in the no-trend 251 experiment is compounded by the apparent drying below $700 \mathrm{mb}$ amounting to $~ 10 \%$ in 252 relative humidity (Figure $7 \mathrm{~b}$ ). Thus, the combination of stabilization and drying in the 253 lower troposphere, in addition to the weakening of the upper-level trough and wave train, 254 supports the substantial rainfall reduction simulated by the no-trend experiment due to 255 reduced conditional instability.

\section{Concluding remarks}

258 We explored the meteorological and climatic conditions accompanying the June 
2592013 rainstorm event in northern India and analyzed past cases that feature similar upper-

260 level circulation settings. The June 2013 event appears to be collaboratively generated by

261 three factors: (a) an upper-level short-wave train with a cyclonic circulation over northern

262 India leading to cold air intrusion, (b) a strong monsoon trough supplying moist air

263 towards the Himalayan foothills, and (c) orographic lifting. The upper-level cold air

264 intrusion enhances instability and subsequently increases rainfall intensity in the region.

265 Furthermore, climate diagnoses suggest that the formation of the distinct short-wave train

266 is not sporadic, but rather is reinforced by the long-term change in the upper troposphere.

267 Based on the CMIP5 historical experiments, the upper-level wave train pattern revealed

268 in the post-1980 trends is attributed to the increases in greenhouse gases and

269 anthropogenic aerosols. Sensitivity experiments with the WRF model further indicated

270 that the removal of the post-1980 trends in the forcing data leads to substantially reduced

271 ( $80 \%)$ precipitation in the flood region for the 5-day storm period. This estimated

272 rainfall reduction is attributed to two prime factors: (1) suppressed cyclonic circulation in

273 the upper troposphere restoring stability and (2) reduced moisture in the middle to lower

274 troposphere. These processes favor the persistent increase in June rainfall over northern

275 India after the mid-1980s and arguably contribute to the record amount of rainfall 276 received in June 2013.

277 The conclusions reached in this study have implications for future flood 278 management, water planning, and extreme weather prediction in northern South Asia.

279 This study showed that as a result of anthropogenic climate change, the circulation

280 structure has been modified in such a way that significantly aggravates rainstorm

281 occurrences in northern South Asia, hence increasing the severity of floods. Also, the 
282 occurrence of this June 2013 event during pre-monsoon season in northern South Asia,

283 along with the circulation and precipitation trends in June, calls for prevention attention

284 to increasingly frequent and strong rainstorms outside the core monsoon months (i.e.,

285 July-August). Adaptation measures such as developing strategies and policies for flood

286 management in the face of climate-related extreme events are urged. In addition, the

287 amplified upper-level stationary waves and associated dynamics as revealed in this study

288 will need to be represented accurately in the forecasting tools.

289

290 Acknowledgements

291 PRECL Precipitation data and NCEP Reanalysis data were provided by the 292 NOAA/OAR/ESRL PSD, Boulder, Colorado, USA, from their Web site at 293 http://www.esrl.noaa.gov/psd/. We would like to thank Henry Lin for his assistance. J.-H. 294 Yoon is supported by the Office of Science of the U.S. Department of Energy as part of 295 the Earth System Modeling program. PNNL is operated for the Department of Energy by 296 Battelle Memorial Institute under Contract DEAC05-76RLO1830. 
$298 \quad$ List of Tables

299

300 Table 1: CMIP5 (the Coupled Model Intercomparison Project Phase 5) models used in the 301 attribution analysis.

302

303 


\section{List of Figures}

Figure 1: Five-day mean wind (vectors) and relative vorticity (shadings) fields averaged over 8-12 June at (a) $200 \mathrm{mb}$ and (b) $700 \mathrm{mb}$. for the pre-storm period. (c)-(d) Same as (a)-(b) but for the storm period of 13-17 June. (e)-(f) Same as (a)-(b) but for the poststorm period of 18-22 June. The Indian state of Uttarakhand is outlined (approximately) by the red box.

Figure 2: CMORPH precipitation averaged for (a) the storm event of 13-17 June 2013 and (b) the composite of five past events with similar circulation settings (see text). (c)(d) Similar to (a)-(b) but for the $200 \mathrm{mb}$ geopotential anomalies (HGT), with the longterm mean removed. (e)-(f) Same as (c)-(d) but for the $700 \mathrm{mb}$ geopotential anomalies.

Figure 3: (a) Time series of June precipitation averaged over the Uttarakhand region (red box in Figure 1) superimposed with a 20 -year running mean (black line) and a linear trend after 1988 (red line). The 2013 amount is highlighted in red, indicating its record status. (b) The spatial pattern of the post-1988 linear trend (slope) in the $200 \mathrm{mb}$ geopotential height(HGT); unit is meter per 25 years. Stippling indicates regions exceeding 90\% statistical confidence. (c) The 5-day mean $200 \mathrm{mb}$ geopotential height anomalies of 13-17 June 2013.

Figure 4: The 1980-2005 linear trend in the $200 \mathrm{mb}$ geopotential height (HGT) simulated by (a) the all forcing, (b) the natural forcing, (c) the GHG forcing, and (d) the aerosols forcing experiments of 10 CMIP5 models CMIP5 models. The unit is meter of total change over the 1980-2005 period. Stippling indicates regions exceeding 90\% statistical confidence.

Figure 5: Time series of June surface temperature (2 meter) averaged over the Uttarakhand region (red box in Figure 1), superimposed with the post-1988 linear trend (red line).

Figure 6: Daily precipitation averaged for 13-17 June 2013 from (a) CMORPH, (b) the WRF control experiment, and (c) the no-trend experiment. (d) Percentage of precipitation reduction between the no-trend and control experiments; only the reduction in the notrend experiment is shown. (e) 3-hour precipitation derived from CMORPH (blue), the control (black) and no-trend (red) experiments in Uttarakhand (boxed area).

Figure 7: Vertical profiles of (a) potential temperature lapse rate and (b) relative humidity averaged in Uttarakhand from the control (black) and no-trend (red) experiments averaged for 13-17 June 2013. 
Table 1. CMIP5 (the Coupled Model Intercomparison Project Phase 5) models used in the attribution analysis

\begin{tabular}{|c|c|c|c|}
\hline Acronym & Full name & $\begin{array}{l}\text { Number of } \\
\text { ensemble }\end{array}$ & Developers \\
\hline CanESM & $\begin{array}{l}\text { Canadian Centre for Climate } \\
\text { modeling and Analysis The } \\
\text { second Generation Earth } \\
\text { System Model } 2\end{array}$ & 5 & Canadian Centre for Climate Modelling and Analysis \\
\hline CCSM4 & $\begin{array}{l}\text { Community Climate System } \\
\text { Model version } 4\end{array}$ & 3 & National Center for Atmospheric Research \\
\hline \multirow{2}{*}{$\begin{array}{l}\text { CNRM- } \\
\text { CM5 }\end{array}$} & \multirow{2}{*}{$\begin{array}{l}\text { National Centre } \begin{array}{r}\text { for } \\
\text { Meteorological } \\
\text { Coupled Model } 5\end{array}\end{array}$} & 6 & Centre National de Recherches Meteorologiques \\
\hline & & & Avancees en Calcul Scientifique, France \\
\hline $\begin{array}{l}\text { GFDL- } \\
\text { CM3 }\end{array}$ & $\begin{array}{l}\text { Geophysical Fluid Dynamics } \\
\text { Laboratory Coupled Physical } \\
\text { Model } 3\end{array}$ & 3 & NOAA, Geophysical Fluid Dynamics Laboratory \\
\hline $\begin{array}{l}\text { GFDL- } \\
\text { ESM2 }\end{array}$ & $\begin{array}{lrr}\text { Geophysical } & \text { Fluid } & \text { Dynamics } \\
\text { Laboratory } & \text { Earth } & \text { System } \\
\text { Model } 2 & & \end{array}$ & 1 & NOAA, Geophysical Fluid Dynamics Laboratory \\
\hline CSIRO & $\begin{array}{l}\text { Commonwealth } \\
\text { Industrial } \\
\text { Organization }\end{array}$ & 4 & $\begin{array}{l}\text { Commonwealth Scientific and Industrial Research } \\
\text { Organization/Queensland Climate Change Centre of } \\
\text { Excellence (CSIRO-QCCCE) }\end{array}$ \\
\hline FGOALS & $\begin{array}{l}\text { Flexible Global Ocean- } \\
\text { Atmosphere-Land System }\end{array}$ & 1 & $\begin{array}{l}\text { Institute of Atmospheric Physics, Chinese Academy } \\
\text { of Sciences }\end{array}$ \\
\hline GISS-E2 & $\begin{array}{l}\text { Goddard Institute for Space } \\
\text { Studies Model E2 }\end{array}$ & 3 & NASA, Goddard Institute for Space Studies \\
\hline IPSL-CM5 & $\begin{array}{l}\text { Institute Pierre Simon Laplace } \\
\text { Coupled Model } 5\end{array}$ & 3 & Institute Pierre-Simon Laplace \\
\hline NorESM1 & $\begin{array}{l}\text { Norwegian } \quad \text { Earth } \quad \text { System } \\
\text { Model 1 }\end{array}$ & 1 & Norwegian Climate Centre (NCC) \\
\hline
\end{tabular}


Chen, M., P. Xie, J. Janowiak, and P. Arkin, 2002: Global land precipitation: A 50-yr REFERENCES monthly analysis based on gauge observations. J. Hydrometeorol., 3, 249-266.

358 Community Atmosphere Model version 3 (CAM3). J. Clim., 19, 2144-2161.

359 Dubey, C. S., D. P. Shukla, A. S. Ningreichon, and A. L. Usham, 2013: Orographic 360 control of the Kedarnath disaster. Curr. Sci., 105, 1474-1476.

361 Hong, C., H. Hsu, N. Lin, and H. Chiu, 2011: Roles of European blocking and tropical362 extratropical interaction in the 2010 Pakistan flooding. Geophys. Res. Lett., 38, L13806.

363 Houze, R. A., Jr., K. L. Rasmussen, S. Medina, S. R. Brodzik, and U. Romatschke, 2011: 364 Anomalous Atmospheric Events Leading to the Summer 2010 Floods in Pakistan. Bull. 365 Am. Meteorol. Soc., 92, 291-298.

366 Joseph, S. and Coauthors, , 2014: North Indian heavy rainfall event during June 2013: 367 diagnostics and extended range prediction. Clim. Dyn. , 10. 1007/s00382-014-2291-5, in $368 \quad$ press

369 Joyce, R., J. Janowiak, P. Arkin, and P. Xie, 2004: CMORPH: A method that produces 370 global precipitation estimates from passive microwave and infrared data at high spatial 371 and temporal resolution. J. Hydrometeorol., 5, 487-503.

372 Kalnay, E. and Coauthors, , 1996: The NCEP/NCAR 40-year reanalysis project. Bull. Am. 373 Meteorol. Soc., 77, 437-471.

374 Kanamitsu, M., W. Ebisuzaki, J. Woollen, S. Yang, J. Hnilo, M. Fiorino, and G. Potter, 375 2002: NCEP-DOE AMIP-II reanalysis (R-2). Bull. Am. Meteorol. Soc., 83, 1631-1643. 
376 Lau, W. K. M., and K. Kim, 2012: The 2010 Pakistan Flood and Russian Heat Wave:

377 Teleconnection of Hydrometeorological Extremes. J. Hydrometeorol., 13, 392-403.

378 Lin, Y., and B. A. Colle, 2011: A New Bulk Microphysical Scheme That Includes Riming

379 Intensity and Temperature-Dependent Ice Characteristics. Mon. Weather Rev., 139, 10133801035.

381 Martius, O. and Coauthors, , 2013: The role of upper-level dynamics and surface 382 processes for the Pakistan flood of July 2010. Q. J. R. Meteorol. Soc., 139, 1780-1797.

383 Najar, N. and S. Masood, Sept. 8, 2014: India and Pakistan Strain as Flooding Kills

384 Hundreds. The New York Times, 2014,

385 http://www.nytimes.com/2014/09/09/world/asia/hundreds-dead-in-flooding-in-india-and386 pakistan.html?_r=0.

387 Nakanishi, M., and H. Niino, 2006: An improved mellor-yamada level-3 model: Its 388 numerical stability and application to a regional prediction of advection fog. Bound. 389 Layer Meteorol., 119, 397-407.

390 Rasmussen, K. L., A. J. Hill, V. E. Toma, M. D. Zuluaga, P. J. Webster, and R. A. Houze 391 Jr, 2014: Multiscale analysis of three consecutive years of anomalous flooding in 392 Pakistan. Quarterly Journal of the Royal Meteorological Society, DOI: 10.1002/qj.2433

393 Singh, D. and Coauthors, , 2014: Severe precipitation in Northern India in June 2013:

394 causes, historical context, and changes in probability. Explaining Extreme Events of 2013

395 From A Climate Perspective: Special Supplement to the Bulletin of the American 396 Meteorological Society, 95, 58-61.

397 Taylor, K. E., R. J. Stouffer, and G. A. Meehl, 2012: An Overview of Cmip5 and the 398 Experiment Design. Bull. Am. Meteorol. Soc., 93, 485-498. 
399 Wang, S., R. E. Davies, R. R. Gillies, and J. Jin, 2011a: Changing Monsoon Extremes and 400 Dynamics: Example in Pakistan. NOAA NWS, Science \& Technology Infusion Climate 401 Bulletin, J. Zhao and W. Higgins eds., 61-68.

402 Wang, S., R. E. Davies, and R. R. Gillies, 2013: Identification of extreme precipitation 403 threat across midlatitude regions based on short-wave circulations. Journal of 404 Geophysical Research-Atmospheres, 118, 11059-11074.

405 Wang, S., R. E. Davies, W. Huang, and R. R. Gillies, 2011b: Pakistan's two-stage 406 monsoon and links with the recent climate change. J. Geophys. Res. -Atmos., 116, 407 D16114.

408 


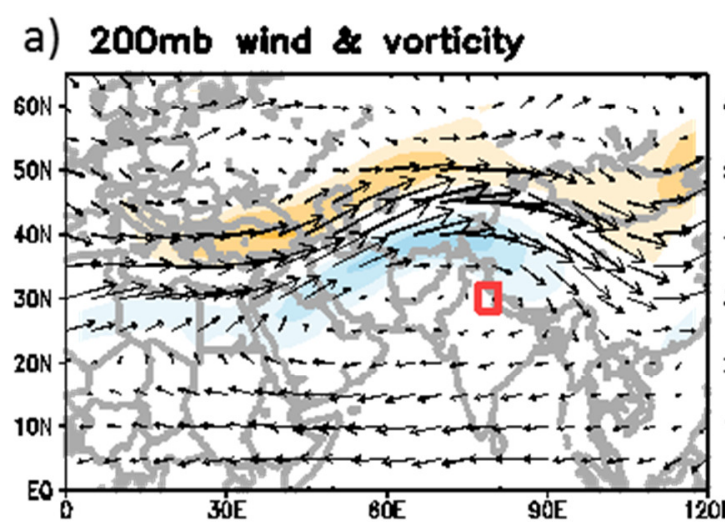

C) $200 \mathrm{mb}$ wind vorticity

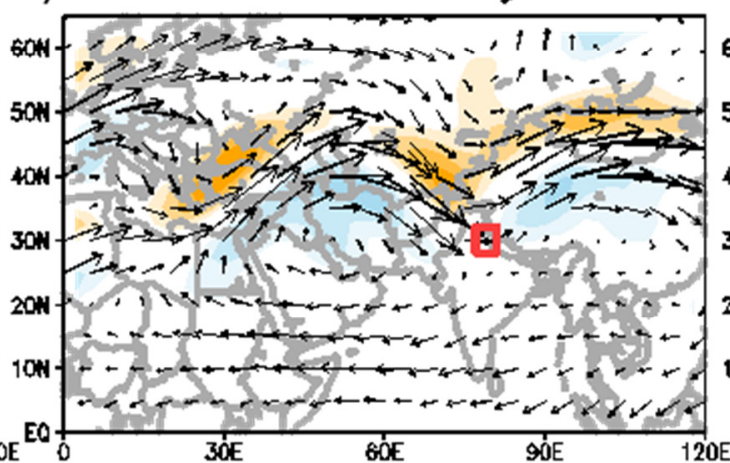

\section{e) $200 \mathrm{mb}$ wind \& vorticity}

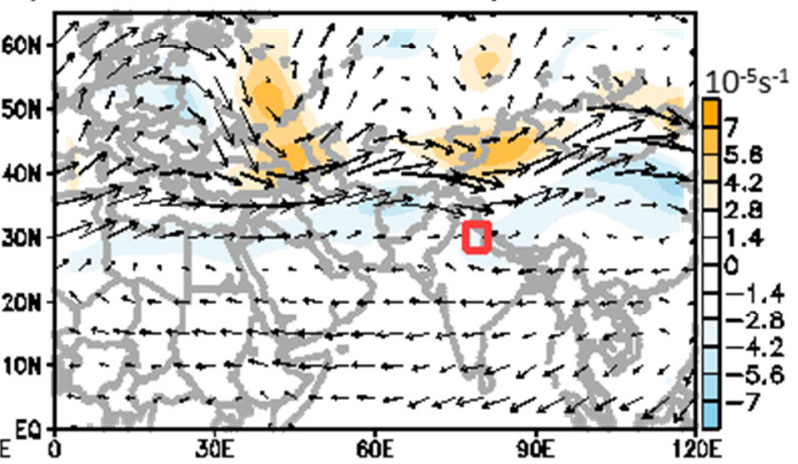

b) $700 \mathrm{mb}$ wind \& vorticity

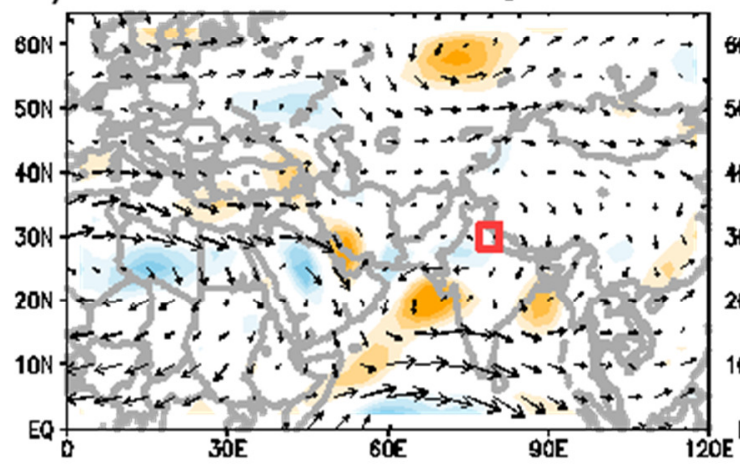

d) $700 \mathrm{mb}$ wind \& vorticity

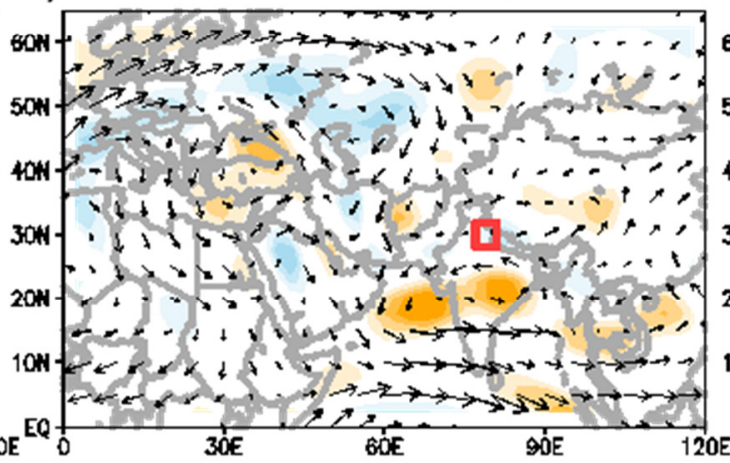

f) $700 \mathrm{mb}$ wind \& vorticity

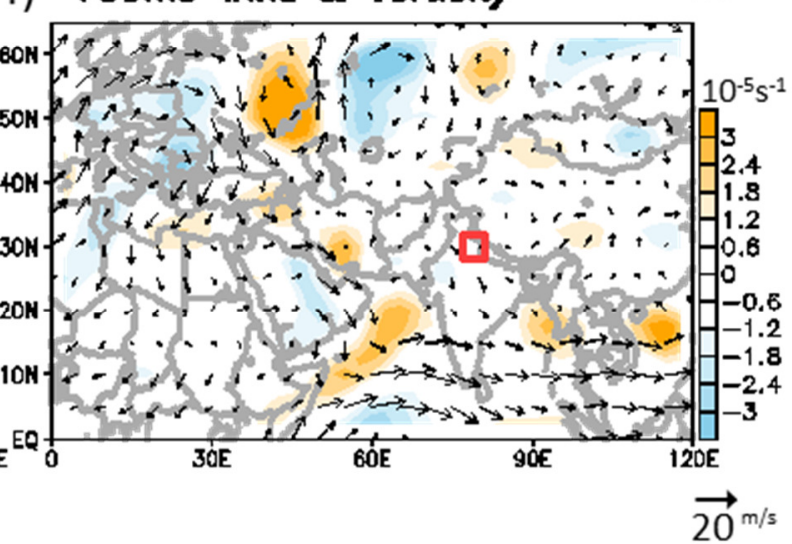

409

410

411

412

413
Figure 1: Five-day mean wind (vectors) and relative vorticity (shadings) fields averaged over 8-12 June at (a) $200 \mathrm{mb}$ and (b) $700 \mathrm{mb}$. for the pre-storm period. (c)-(d) Same as (a)-(b) but for the storm period of 13-17 June. (e)-(f) Same as (a)-(b) but for the post-storm period of 18-22 June. The Indian state of Uttarakhand is outlined (approximately) by the red box. 
a) ${ }_{600}$ Precipitation 13-17 June 2013

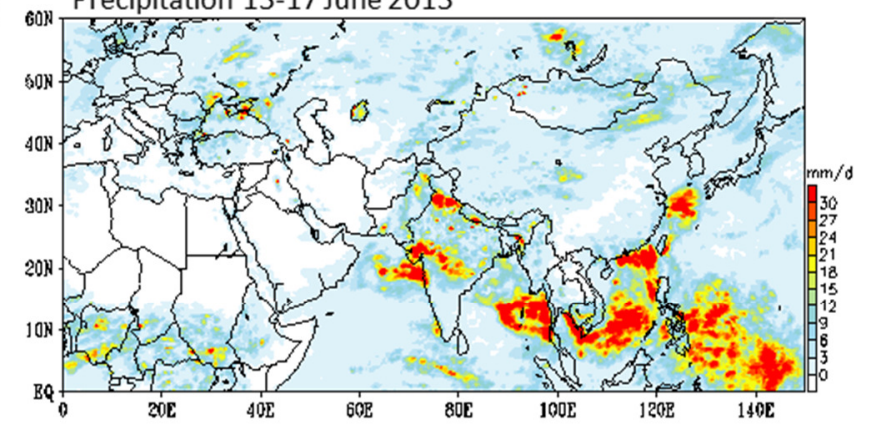

c) $B 0 \mathrm{~N} 200 \mathrm{mb}$ HGT 13-17 June 2013

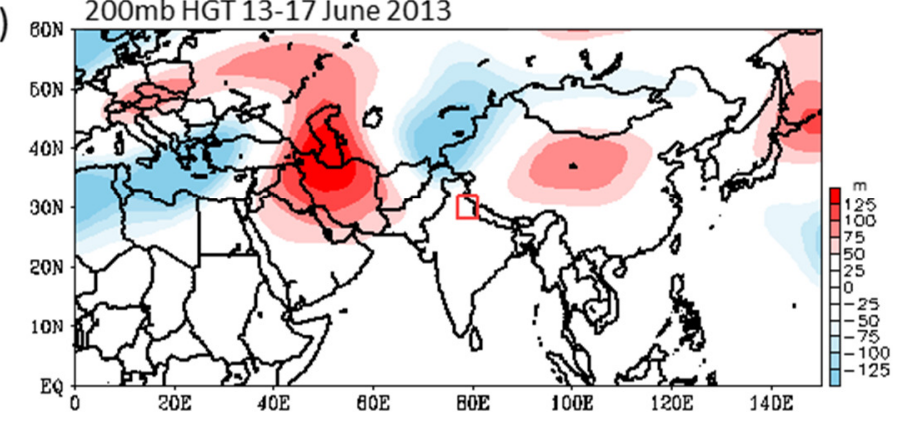

e) $\mathrm{BDN} 700 \mathrm{mb}$ HGT 13-17 June 2013

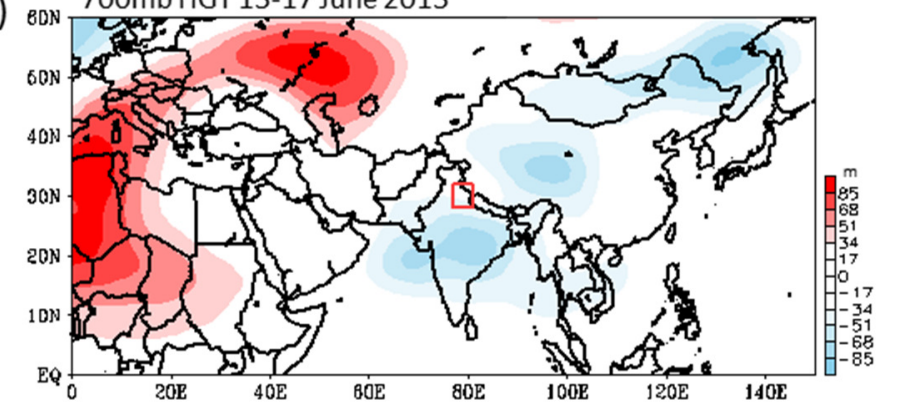

b) $60 \mathrm{~N}$ Precipitation composite

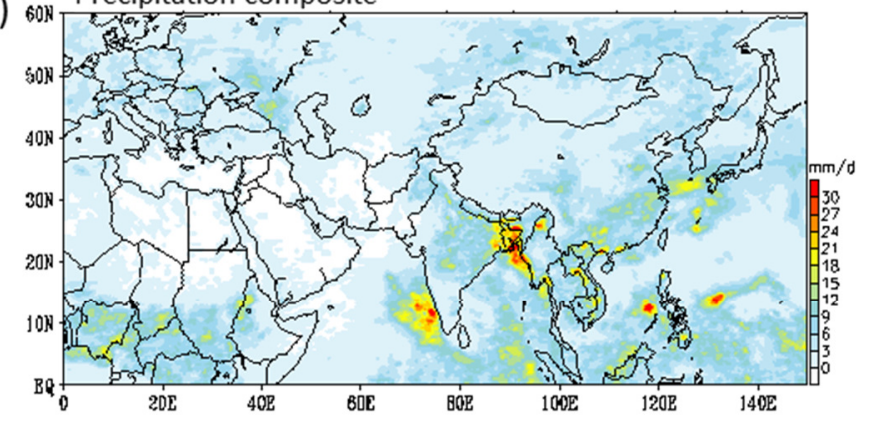

d) ${ }_{60 \mathrm{~N}} 200 \mathrm{mb}$ HGT composite
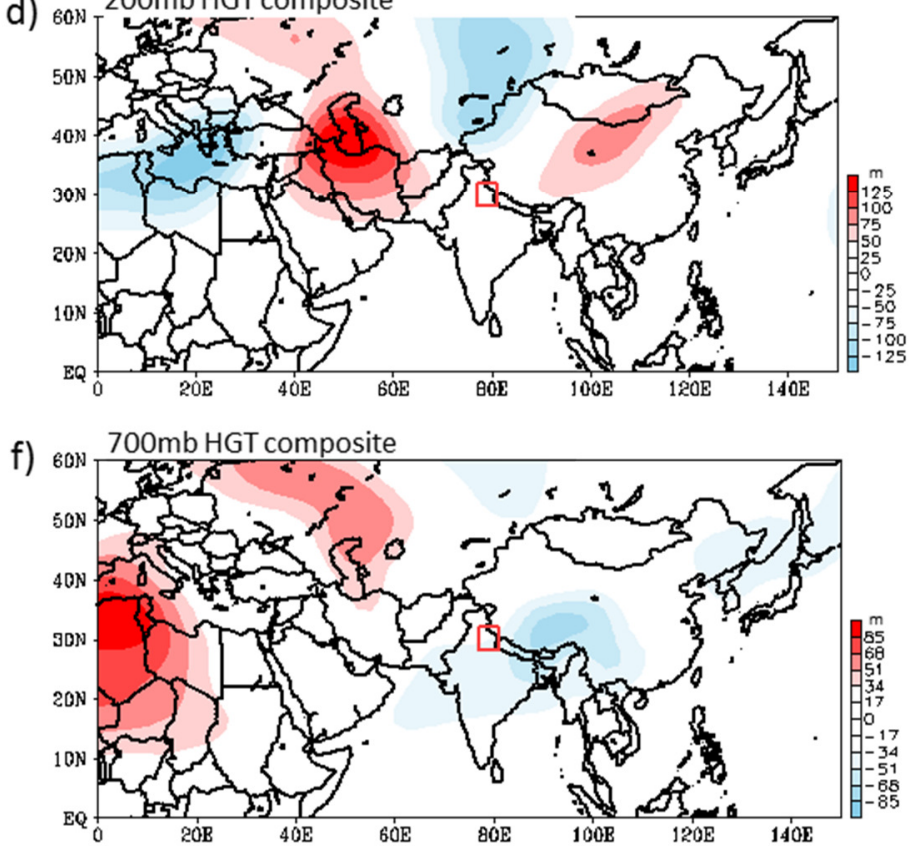

Figure 2: CMORPH precipitation averaged for (a) the storm event of 13-17 June 2013 and (b) the composite of five past events with similar circulation settings (see text). (c)-(d) Similar to (a)-(b) but for the $200 \mathrm{mb}$ geopotential anomalies (HGT), with the long-term mean removed. (e)-(f) Same as (c)-(d) but for the $700 \mathrm{mb}$ geopotential anomalies. 


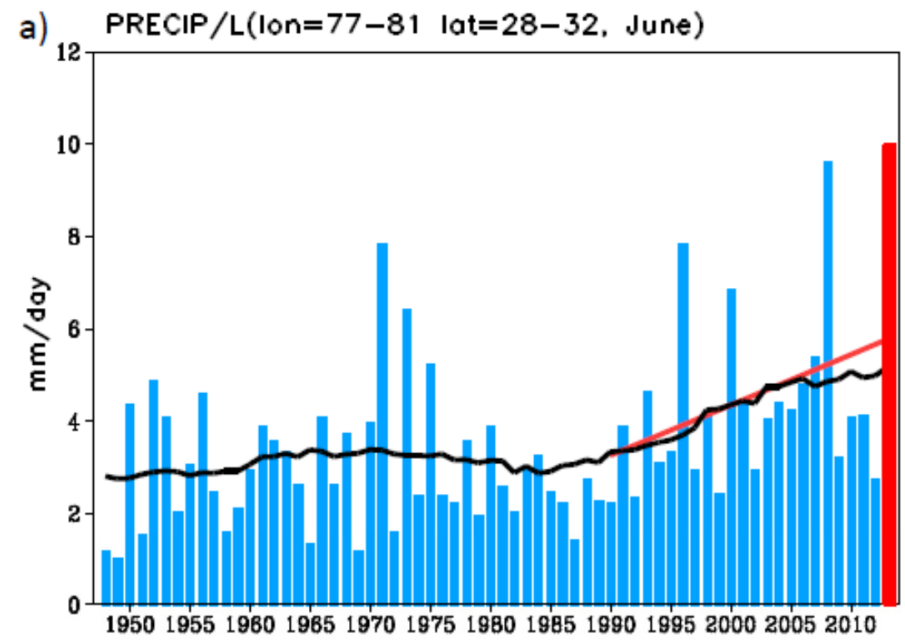

b) Trend in June $200 \mathrm{mb}$ height after 1988

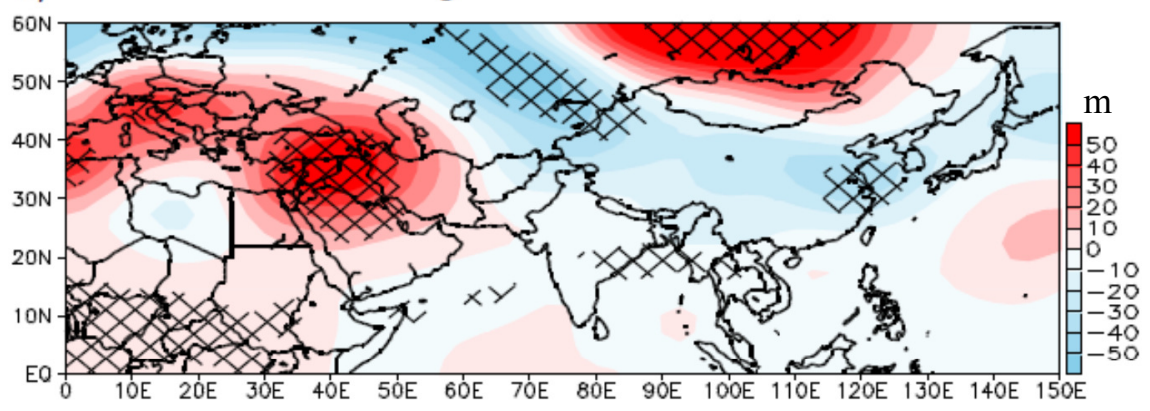

c) Case $2013 \mathrm{HGT} 200 \mathrm{hPa}$

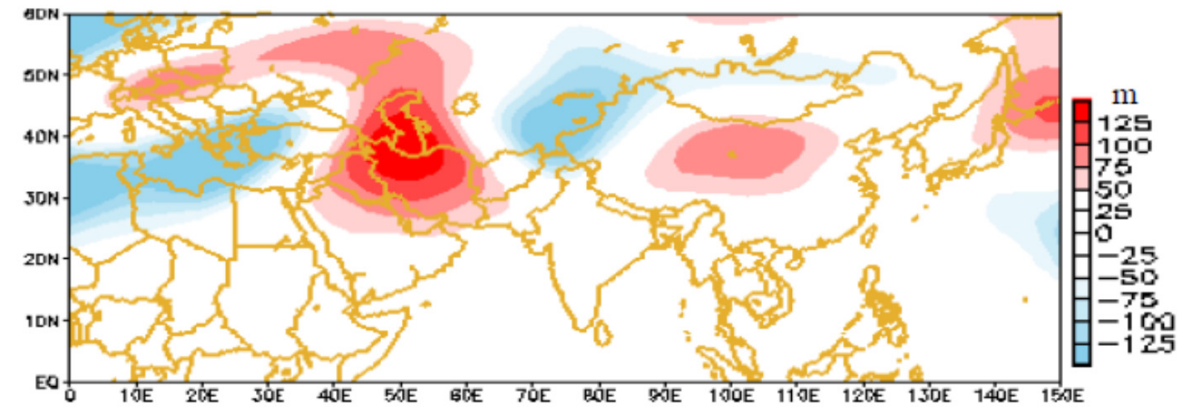

Figure 3: (a) Time series of June precipitation averaged over the Uttarakhand region (red box in Figure 1) superimposed with a 20-year running mean (black line) and a linear trend after 1988 (red line). The 2013 amount is highlighted in red, indicating its record status. (b) The spatial pattern of the post-1988 linear trend (slope) in the $200 \mathrm{mb}$ geopotential height (HGT); unit is meter per 25 years. Stippling indicates regions exceeding $90 \%$ statistical confidence. (c) The 5-day mean $200 \mathrm{mb}$ geopotential height anomalies of 13-17 June 2013. 
(a) All

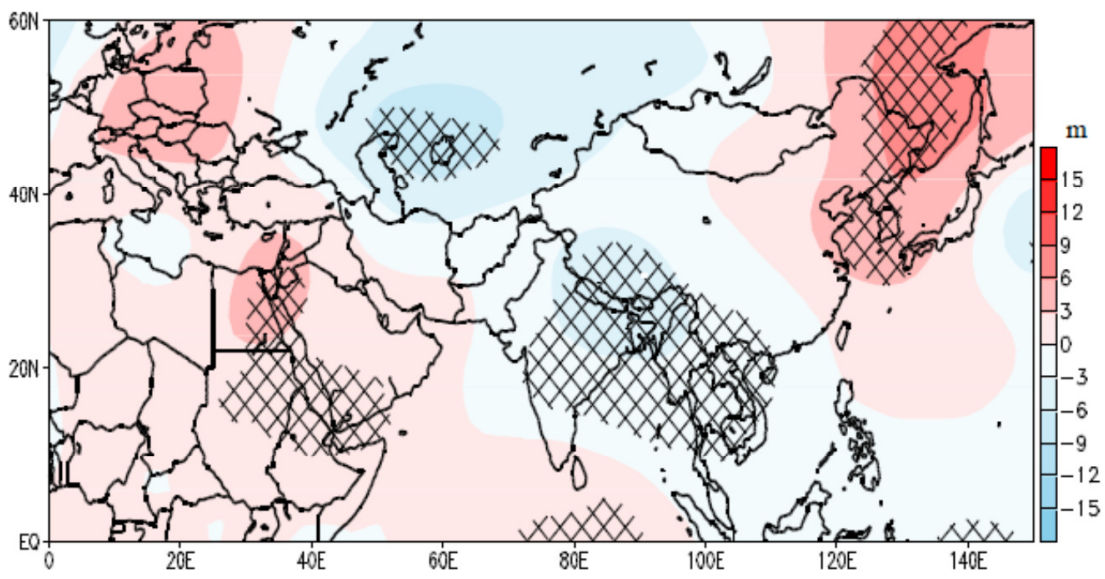

(b) Nat

421 (c) GHG

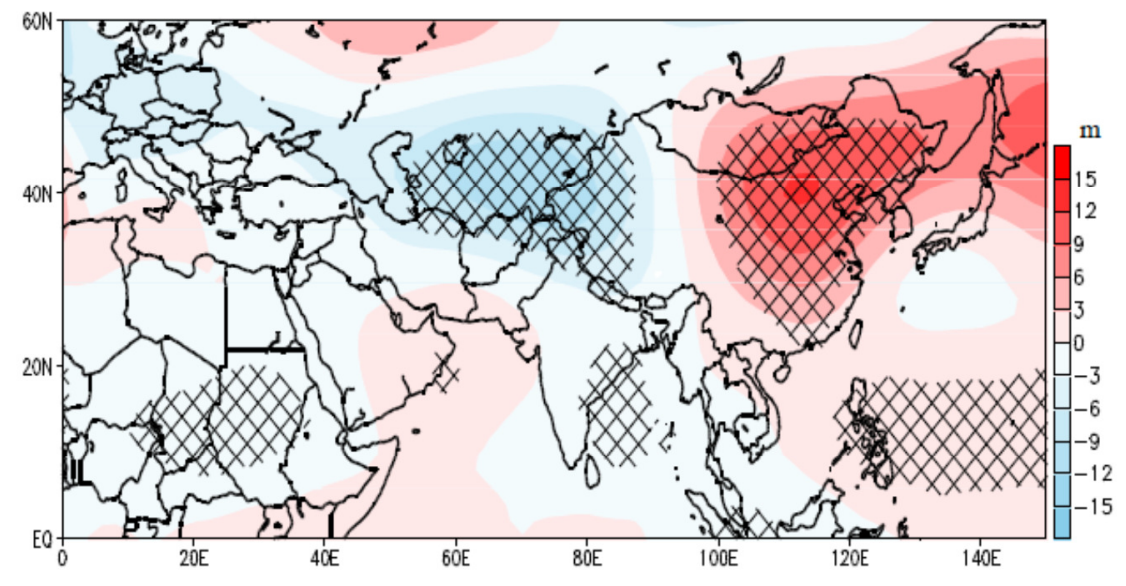

(d) Aero

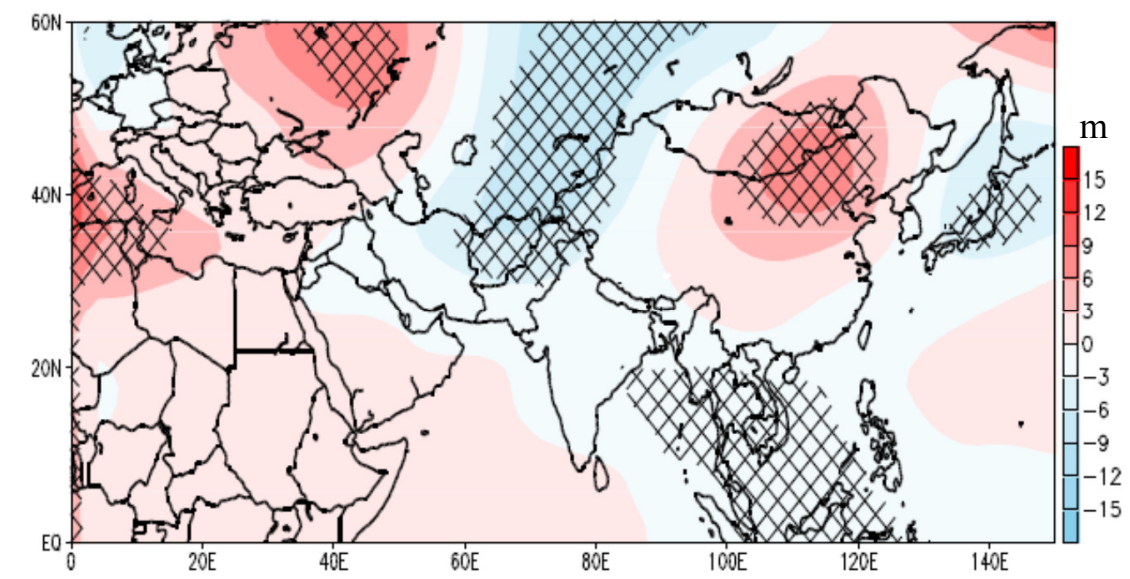

Figure 4: The 1980-2005 linear trend in the $200 \mathrm{mb}$ geopotential height (HGT) simulated by (a) the all forcing, (b) the natural forcing, (c) the GHG forcing, and (d) the aerosols forcing experiments of 10 CMIP5 models CMIP5 models. The unit is meter of total change over the 1980-2005 period. Stippling indicates regions exceeding 90\% statistical confidence. 


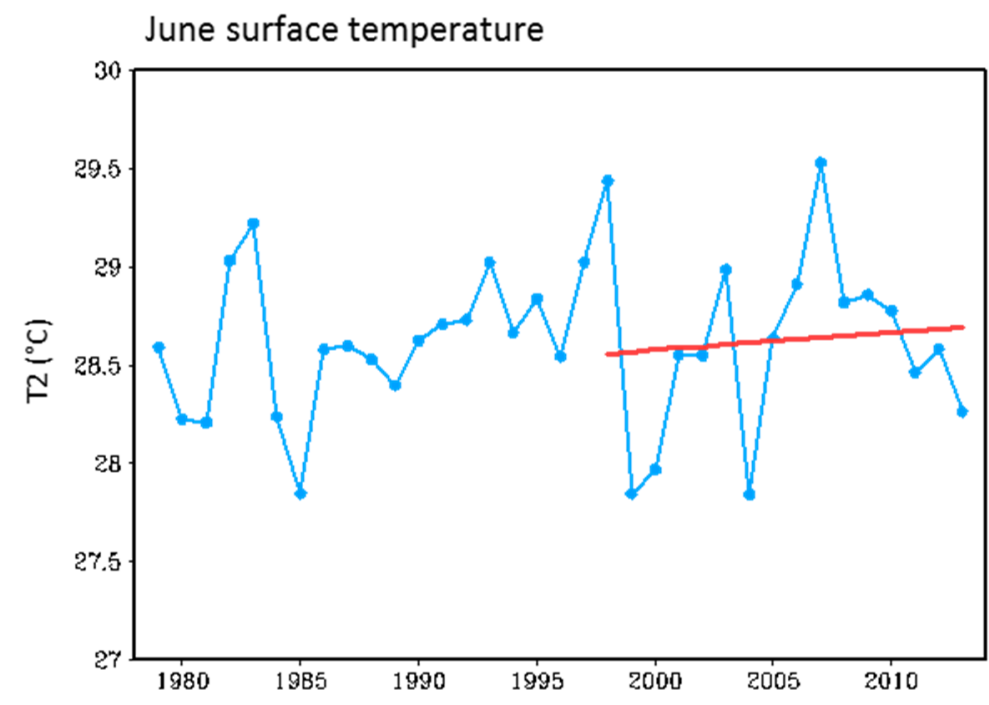
with the post-1988 linear trend (red line). 

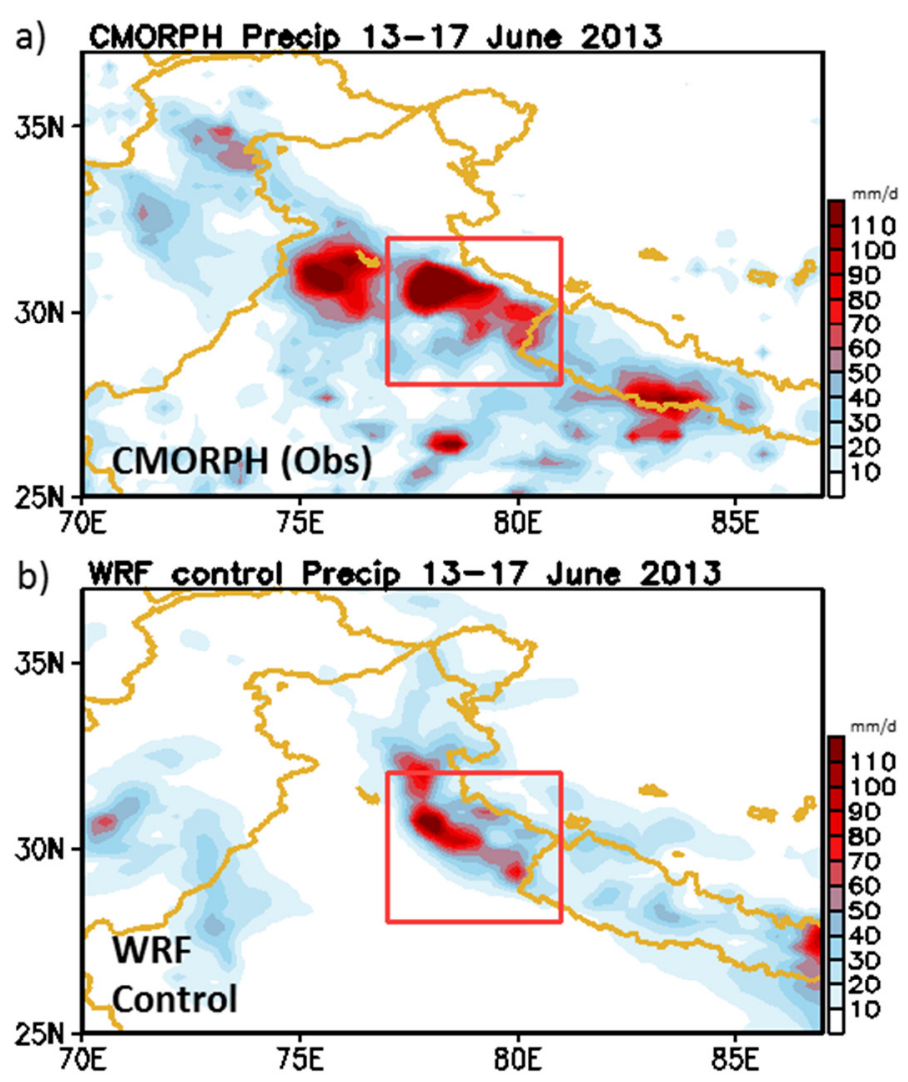

c) WRF no-trend Precip 13-17 June 2013
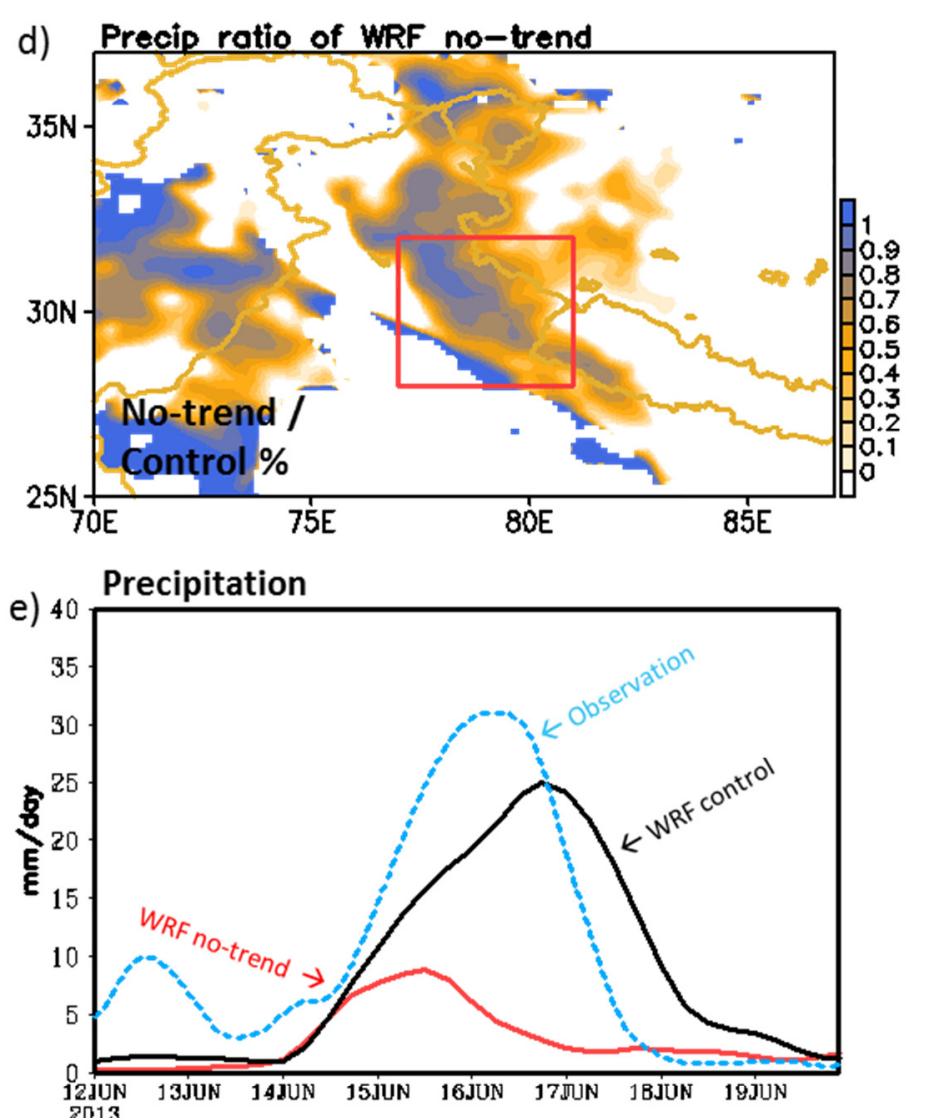

Figure 6: Daily precipitation averaged for 13-17 June 2013 from (a) CMORPH, (b) the WRF control experiment, and (c) the no-trend experiment. (d) Percentage of precipitation reduction between the no-trend and control experiments; only the reduction in the no-trend experiment is shown. (e) 3-hour precipitation derived from CMORPH (blue), the control (black) and no-trend (red) experiments in Uttarakhand (boxed area). 
Figure 7: Vertical profiles of (a) potential temperature lapse rate and (b) relative humidity averaged in Uttarakhand from the control
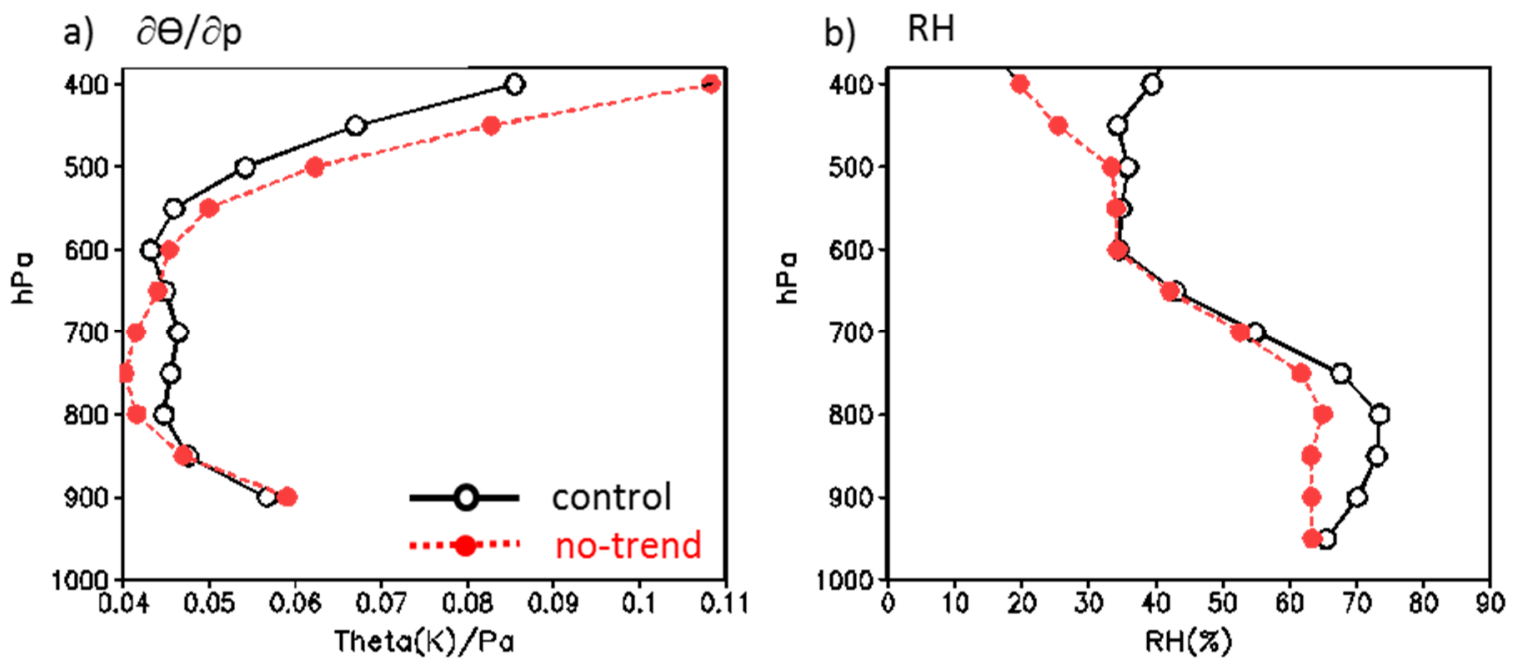

(black) and no-trend (red) experiments averaged for 13-17 June 2013. 